Mide Kanserine Eşlik Eden Peritoneal Karsinomatozisde Sitoredüktif Cerrahi ve Hipertermik Intraperitoneal Kemoterapi Deneyimimiz: Tek Merkez Ardışık 10 Olgunun Analizi

\title{
Cytoreductive Surgery and Hyperthermic Intraperitoneal Chemoterapy for Advance Gastric Cancer Associated Peritoneal Carcinomatosis Single Centre Unit for 10 Consecutive Patients
}

\author{
(1) Özgül Düzgün, (1) Sema Yüksekdağ, (1) Murat Kalın, (1) Şenol Çomoğlu* , (1) Semra Yanık**, \\ (1) Ömer Faruk Özkan, (1) Neşet Köksal***
}

Sağlık Bilimleri Üniversitesi, Ümraniye Eğitim ve Araştırma Hastanesi, Genel Cerrahi Kliniği, İstanbul, Türkiye

*Sağlık Bilimleri Üniversitesi, Ümraniye Eğitim ve Araştırma Hastanesi, Enfeksiyon Hastalıkları ve Klinik Mikrobiyoloji Kliniği, İstanbul, Türkiye

**Sağlık Bilimleri Üniversitesi, Ümraniye Eğitim ve Araştırma Hastanesi, Anestezi ve Reanimasyon Kliniği, istanbul, Türkiye

***Yeditepe Üniversitesi Tıp Fakültesi Hastanesi, Genel Cerrahi Kliniği, İstanbul, Türkiye

Öz

\begin{abstract}
Amaç: Sitoredüktif cerrahi ile beraber hipertermik intraperitoneal kemoterapi uygulamasının ileri evre abdominal kanserlerde sağ kalıma olumlu etkisi olduğu gösterilmiştir. Bu konuda özellikle son iki dekatta mide kanseriyle de alakalı güncel bilgiler mevcut olup bu çalışmada peritoneal karsinomatozun eşlik ettiği mide kanser olgularında sitoredüktif cerrahi ve hipertermik intraperitoneal kemoterapi deneyimimizi literatür eşliğinde sunmayı amaçladık.

Yöntemler: Haziran 2017-Kasım 2018 tarihleri arasında mide kanseri tanısı almış, yapılan tetkiklerinde peritoneal karsinomatozisin eşlik ettiği hastalar çalışmaya dahil edildi. Prospektif olarak toplanan verilerin değerlendirilmesi ile hastaların demografik verileri, kısa dönem takip sonuçları,ameliyat bulguları,peritoneal karsinomatozis indeks skoru, rezeksiyon tamlık skoru, morbidite ve mortalite oranları analiz edildi.

Bulgular: Mide kanseri zemininde peritoneal karsinomatozis gelişen 10 olgu çalışmaya dahil edilmiş olup hastaların yaş ortalaması 60,3 idi. Cinsiyet açısından bakıldığında, yedisi erkek üçü kadındı. Hastaların ortalama takip süresi 6 ay olup en az 1 en çok 15 aydı. Postoperatif bir olguda anastomoz kaçağı gelişti. Diğer dokuz olguda mortaliteye neden olacak herhangi bir morbidite gelişmedi.
\end{abstract}

Abstract

Aim: Hyperthermic intraperitoneal chemotherapy with cytoreductive surgery has a positive effect on survival in advanced abdominal cancers. We aimed to present our experience with cytoreductive surgery and hyperthermic intraperitoneal chemotherapy in gastric cancer patients with peritoneal carcinomatosis and a review of the literature.

Methods: Ten patients (seven male, three female) who were diagnosed with gastric cancer between June 2017 and November 2018 were included in the study. Data on demographic characteristics, short-term follow-up results, surgical findings, peritoneal carcinomatosis index score, completeness of cytoreduction score, and morbidity and mortality rates were retrospectively analyzed.

Results: The mean age of the patients was 60.3 years. The mean follow-up period was six months (1-15 months). One patient developed an anastomotic leak. In the other nine cases, there was no morbidity leading to mortality.

Conclusion: While gastric cancer with peritoneal carcinomatos has a poor survival, less than six months with non-operative approach, treatment with cytoreductive surgery and hyperthermic
Yazışma Adresi/Address for Correspondence: Özgül Düzgün, Sağlık Bilimleri Üniversitesi Ümraniye Eğitim ve Araştırma Hastanesi, Genel Cerrahi Kliniği, istanbul, Türkiye Tel.: +90 5054867187 E-posta: ozgulduzgun@gmail.com ORCID: orcid.org/0000-0001-7214-2276 Geliş Tarihi/Received: 07 Şubat 2019 Kabul Tarihi/Accepted: 07 Mart 2019
Telif Hakkı 2019 İstanbul Haseki Eğitim ve Araştırma Hastanesi Haseki Tıp Bülteni, Galenos Yayınevi tarafından yayınlanmıştır.

${ }^{\circ}$ Copyright 2019 by The Medical Bulletin of istanbul Haseki Training and Research Hospital The Medical Bulletin of Haseki published by Galenos Yayınevi. 
Öz

Sonuç: Peritoneal karsinomatozisin eşlik ettiği mide kanserlerinde sitoredüktif cerrahi ve hipertermik intraperitoneal kemoterapi uygulamasıyla non operatif sağkalımı 3-6 ay arasında olan bu hasta grubunda, daha iyi sağkalım sağlandığı görülmüştür. Bu konuda sınırlı sayıda hastamızla yaptığımız çalışmada ilk sonuçlarımız yüz güldürücü olup, bu konuda yapılacak olan multimerkez randomize çalışmalara ihtiyaç vardır.

Anahtar Sözcükler: Mide kanseri, peritoneal karsinomatozis, sitoredüktif cerrahi, hipertermik intraperitoneal kemoterapi

\section{Abstract}

intraperitoneal chemotherapy offers better outcomes and overall survival. Our first results in our study with a limited number of patients are satisfactory and multicentric randomized studies are needed on this subject.

Keywords: Gastric cancer, peritoneal carcinomatosis, cytoreductive surgery, hyperthermic intraperitoneal chemotherapy

\section{Giriş}

Dünya Sağlık Örgütü verilerine göre mide kanseri tüm kanserlerin görülme sıklığı açısından beşinci sırada olup hastalığın tanı sürecindeki gecikmeye ve agresif seyretmesine bağlı olarak kansere bağlı ölümlerde ise üçüncü sırayı almaktadır $(1,2)$. Görülme sıklığı açısından diğer abdominal kaynaklı kanserler, coğrafi dağılım açısından yakın benzerlikler gösterirken, mide kanseri açısından bu durum belirgin olarak farklıdır. Mide kanseri Kuzey Amerika'da ve Avrupa'da daha nadir görülmekte iken; hastalık Çin, Japonya gibi Asya ülkelerinde tüm dünyada görülen mide kanserlerinin yaklaşık \%70'ini oluşturmaktadır (3). Bu farklılık araştırmacıların özellikle Asya bölgesindeki beslenme alışkanlıklarını (tütsülenmiş yiyecekler, fazla tuz tüketimi) epidemik nedenleri ve genetik altyapısının sorgulamasına neden olmuştur.

Yine mide kanserinin Asya ülkelerinde fazla görülmesi, tarama programlarında yer almasına neden olmuştur. Örneğin Japonya'da mide kanserlerinin önlenmesi için erken üst gastrointestinal sistem endoskopik taramalarını gündeme getirmiş ve bu tarama protokolleri ciddi bir şekilde yaygınlaşmıştır. Yine hastalığın bu ülkede fazla görülmesi ve bu kadar agresif ve mortal seyreden bu kanserin tedavi stratejilerinde ciddi ilerlemelerin olmasını sağlamıştır (4).

Tedavi stratejileri açından bakıldığında; lokal ileri mide tümörlerinin, ilk yapılan mide rezeksiyonları sonrasında hastalığın erken dönemde nüks etmesi ve peritoneal karsinomatozis (PK) tablosuna neden olması daha radikal rezeksiyonların yapılmasına ve halen günümüzde geçerliliğini koruyan mide kanserindeki lenf nodu haritalanmasının tanımlanmasını sağlamıştır (5-7). Radikal ve agresif rezeksiyonlardan sonra dahi nükslerin görülmesi ve tanı anında PK tablosunun olması ayrıca güncel kemoterapotiklerinde tanımlanmasını sağlamıştır (3). Lakin, bu yaklaşımlarla bile ileri evre olgularda hastalıksız sağkalımlarda diğer abdominal kaynaklı kanserlerde elde edilen yüz güldürücü sonuçlar alınamamışır (8).
Son üç dekatta apendiks, kolorektal, mezotelyoma ve over kanserinde tanımlanan sitoredüktif cerrahi ve hipertermik intraperitoneal kemoterapi (SRC + HIPEC) uygulamaları; bu kadar agresif seyreden mide kanserininde tedavisinde kullanıma girmiştir ve bununla alakalı özellikle batı Avrupa ülkelerinden, Çin'de ve Japonya'dan olumlu sonuçlar bildirilmeye başlanmıştır (6,7,9-11). Bu olumlu sonuçlar temel alınaraktan, PK tablosu hariç lokal ileri mide kanserinde bile HIPEC uygulamaları literatürde yer bulmuştur (12). Biz bu çalışmamızda son 2,5 yılda 114 HIPEC uygulamamıdan 10 olguda mide kanseri nedeniyle SRC + HiPEC tedavisi protokolü uyguladığımız hastalarımızın sonuçlarını literatür eşliğinde tartışmayı planladık.

\section{Yöntemler}

23/1/2019 tarihli 2 no'lu etik kurul onayı alınması sonrası Sağlık Bilimleri Üniversitesi Ümraniye Eğitim ve Araştırma Hastanesi Genel Cerrahi Kliniği'nde PK nedeniyle Haziran 2017- Kasım 2018 tarihleri arasında tüm verileri (demografik-preoperatif-operaratif-postoperatif ve takip) prospektif olarak kaydedilip retrospektif olarak analiz edilen SRC + HIPEC yapılan toplam 114 hastadan mide kanseri nedeniyle, karsinomatoz gelişen ve organ invazyonu, serozal implantların eşlik ettiği primer ve nüks olgular değerlendirilmeye alındı. Bu olgular dışındaki ve verilerinde eksiklik olan tüm olgular çalışma dışı bırakıldı.

Olguların; demografik verileri, (yaş, cinsiyet, eşlik eden ek hastalık, ASA skoru) rekürren ve primer olup olmaması, sistemik kemoterapi/radyoterapi alıp almadığı, ameliyat bulguları, ameliyat süresi, peritoneal karsinomatozis indeks (PKi) skoru, rezeksiyon tamlık (CC) skoru, HIPEC'te uygulanan kemoterapi (KT) rejimi, eş zamanlı yapılan senkron rezeksiyonlar, erken ve geç dönemdeki komplikasyonlar (Clavian Dindo Skoru) ve mortalite açısından değerlendirildi.

\section{İstatistiksel Analiz}

Ham verilerden elde edilen datalar IBM SPSS Statistics 22 (IBM SPSS, Türkiye) programına kaydedilerek 
verilerin ortalama mod, median ve yüzdelik dilimlerdeki dağılımı hesaplanarak sonuçlar bölümündeki tablolara kaydedilmiştir. Çalışmamızda herhangi bir karşılaştırma olmadığı için başka bir istatistiksel analiz yapılmamıştır.

\section{Cerrahi Teknik}

Tüm olgulara umbilikus seviyesinden ultrason yardımı ve/veya Hasson trokar tekniği ile kamera portu sokuldu ve PKi skoru (Tablo 1) hesaplandı. Tüm hastaların batın içerisindeki makroskopik metastatik odakları eksize edildi ve ek organ rezeksiyonlarının yanı sıra total gastrektomi R\&Y özefagojejunostomi D2 ve/veya paraaortik lenf nodu diseksiyonları ve komplet sitoredüksiyon uygulandı. Rezeksiyon tamlık skorları (CC skor - Tablo 2) hesaplandı. Bütün ameliyatlar aynı iki cerrah tarafından aynı teknikle gerçekleştirilmiştir. Serimizdeki tüm hastaların özefagojejunal anastomozları 25'lik sirküler staplerle (25-mm circular-stapler Covidien, Autosuture, Mansfield, MA, USA) yapıldı ve anastomozlar iki kat takviye sütürlerle sağlamlaştıııldı. Duodenum, jejenum güdüğü, jejunojejunostomi anastomozları lineer staplerler (GIA 60 mm staplers with DST series Medtronic, Minneapolis, USA) ile gerçekleştirildi ve iki kat takviye sütürler uygulandı. Dalak tutulumu olmayan hastalarda splenik ven-arter ve hilus diseksiyonları tamamlanarak dalak korundu. Tüm

\begin{tabular}{|c|c|c|}
\hline \multicolumn{2}{|c|}{ Abdominal bölgeler } & Lezyonun büyüklüğü \\
\hline 0 & Periumbilikal & \multirow{13}{*}{$\begin{array}{l}\text { Makroskopik tümör yok : Skor } 0 \\
\text { Tümör } 0,5 \mathrm{~cm} \text { 'ye kadar : Skor } 1 \\
\text { Tümör } 5 \mathrm{~cm} \text { 'ye kadar : Skor } 2 \\
\text { Tümor }>5 \mathrm{~cm} \text { veya Konflüans : Skor } 3\end{array}$} \\
\hline 1 & Sağ üst kadran & \\
\hline 2 & Epigastrium & \\
\hline 3 & Sol üst kadran & \\
\hline 4 & Sol flank & \\
\hline 5 & Sol alt kadran & \\
\hline 6 & Pelvis & \\
\hline 7 & Sağ alt kadran & \\
\hline 8 & Sağ flank & \\
\hline 9 & Üst jejenum & \\
\hline 10 & Alt jejenum & \\
\hline 11 & Üst ileum & \\
\hline 12 & Alt ileum & \\
\hline \multicolumn{3}{|c|}{ *Toplam bölge sayısı: 13, PKi: Peritoneal karsinomatozis indeksi skoru: 0-39 } \\
\hline
\end{tabular}

\begin{tabular}{|l|l|}
\hline \multicolumn{2}{|l|}{ Tablo 2. Rezeksiyon tamlık skorunun değerlendirilmesi } \\
\hline CC-0 & Rezidüel nodül yok \\
\hline CC-1 & Rezidüel nodül $<2,5 \mathrm{~mm}$ \\
\hline CC-2 & Rezidüel nodül $>2,5 \mathrm{~mm}$ ve $<2,5 \mathrm{~cm}$ \\
\hline CC-3 & Rezidüel nodül $>2,5 \mathrm{~cm}$ \\
\hline CC: Rezeksiyon tamlık skoru & \\
\hline
\end{tabular}

hastalarda tam D-2 diseksiyon ve paraaortik tutulumu olanlarda D3 lenf nodu diseksiyonu yapıldı (Resim $1 a, 1 b, 1 c)$.

\section{HIPEC Prosedürü}

SRC tamamlandıktan sonra her iki subdiafragmatik alana birer adet outflow, pelvik ve epigastrik alanlarada birer adet outflow ve inflow drenler olmak üzere toplam dört adet dren yerleştirildi. Epigastrik bölgedeki inflow dren komşuluğuna ve pelvik outflow dreninin çevresine ISI probları yerleştirildi. Batın PDS loop No 1 ile continue ve deri stapler ile veya prolen süturlerle kapatılarak intraperitoneal HIPEC işlemine geçildi (Resim 1d). Hastalara 60 dakika boyunca \% $9 \mathrm{NaCl}$ solüsyonu içerisinde cisplatin (CIS) 75 $\mathrm{mg} / \mathrm{m}^{2}$ Vücut yüzey alanı (VYA) + doxorubicin (DOXO) 15 $\mathrm{mg} / \mathrm{m}^{2}$ VYA intraperitoneal olarak uygulandı. Bu işlemler sırasında özefagusa yerleştirilen prob ile intraabdominal vücut sıcaklığı ölçüldü. (Belmont Hyperthermia Pump; Belmont Instrument corporation, Billerica, MA, USA).

\section{Bulgular}

SRC HIPEC data kayıt sisteminden ilgili tarihler arasında yapılan taramada 14 olgu saptanmış olup, PCI skoru perop 20'nin üzerinde saptanan dört olgu inoperabl olarak kabul edilerek sistemik tedavi için tıbbi onkoloji birimine yönlendirildi. Bu olguların takiplerinde üçünde 3 ayda

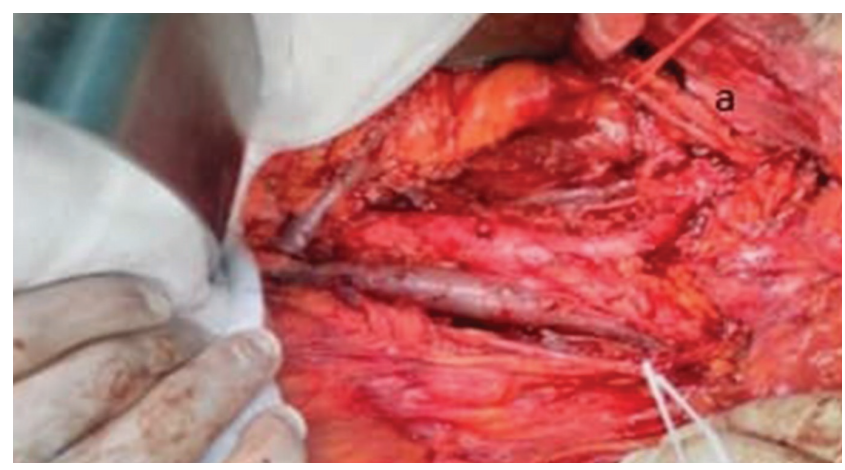

Resim 1a. SRC'de paraaortik lenf nodu diseksiyonu SRC: Sitoredüktif cerrahi

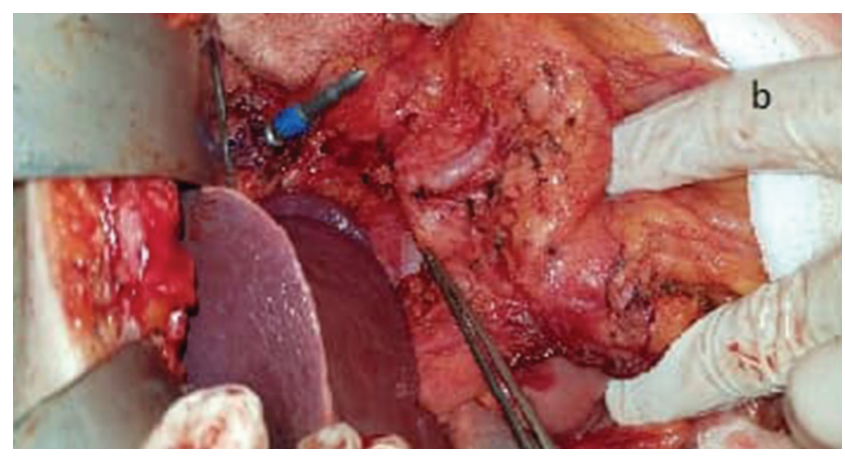

Resim 1b. D2 lenf nodu diseksiyonu ile özefagojejunostomi anastomoz hazırlığı 
mortalite gelişirken bir olgunun tedavisi halen sürmektedir Verileri sisteme kayıtlı olan ve herhangi bir veri eksiği olmayan 10 olgu çalışmamıza dahil edildi.

Hastaların yaş ortalaması 60,3 (45-68, R:23) olup, olguların yedisi (\%70) erkek, üçü (\%30) kadındı. Eşlik eden hastalık açısından değerlendirildiğinde iki (\%20) hastada hipertansiyon, bir (\%10) hastada diabetes mellitus vardı. Bir olgunun özgeçmişinde prostat kanseri nedeniyle 5 yıl önce operasyon hikayesi olup, olguların demografik verileri Tablo 3'te özetlenmiştir.

Hastalarımızın altısı (\%60) primer mide kanseri kaynaklı PK, dördü (\%40) nüks ve bu zeminde karsinomatoz ve organ tutulumu nedeniyle opere edilerek HIPEC uygulanan hastalardı. Nüks gelişen olgular sırasıyla 3 yıl önce, 1 yıl önce ve 7 ay önce opere olmuş olgulardı ve total gastrektomi uygulanmıştı. Dördüncü olgu ise inoperabl kabul edilerek gastrojejunostomi yapılarak, adjuvan tedavi sonrasi tıbbi onkoloji birimince operasyon açısından tarafımıza yönlendirilmişti. Diğer altı hasta neoadjuvan tedavi sonrası tedavisinin düzenlenmesi amacı ile kliniğimize

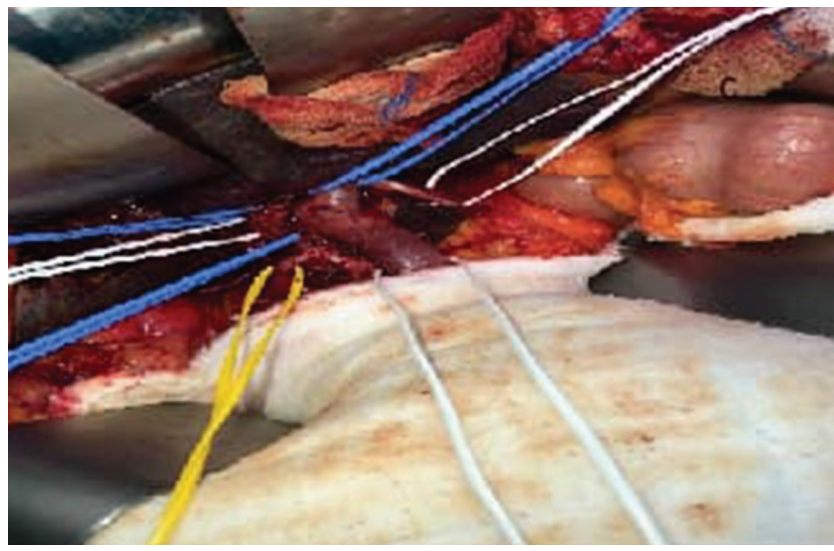

Resim 1c. Hepatoduodenal ligamanın pankreatektomiyle beraber agresif diseksiyonu

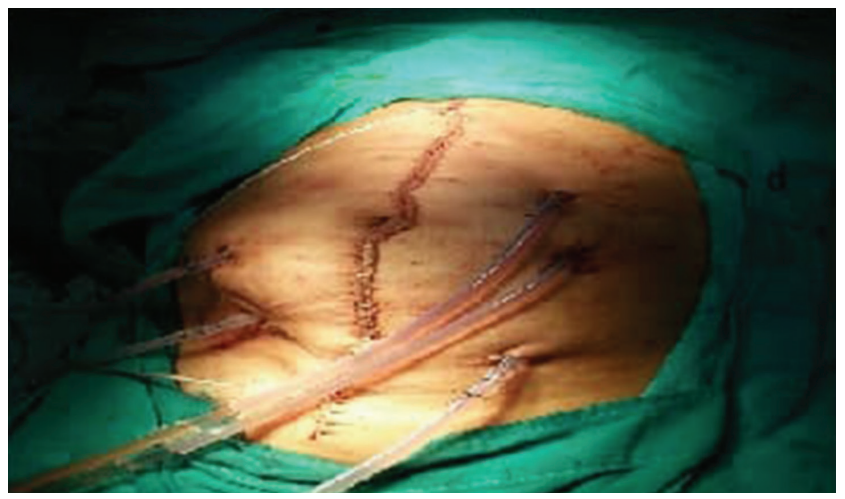

Resim 1d. HIPEC işlemi için drenlerin ve ISI problarının yerleştirilmesi

HIPEC: Hipertermik intraperitoneal kemoterapi yönlendirildi. Olgularımızın geçirilmiş operasyonları, yapılan cerrahi prosedürler, süresi (saat) ve morbidite Tablo 4'de gösterilmiştir.

Olguların peroperatif olarak saptanan $\mathrm{PCl}$ skoru ortalaması ortalaması 9,9 (7-16) olup, primer olgularda ortalama skor 8 iken; sekonder olgularda 12 idi. Tüm olgular rezeksiyon tamlık skoru açısından değerlendirildiğinde; yedi olguda CC 0, ve üç olguda CC 1 skoru elde edilmiştir. En geniş rezeksiyon yapılan olgu mide kanserine ilaveten Familyal Adenomatozis Coli (FAP) olması üzerine total gastrektomi Roux en Y özefagojejunostomi, D2 lenf nodu diseksiyonu + total kolektomi ileoanal J poş anastomoz ve SRC + HIPEC uygulandı. Bu hastanın loop ileostomisi 2. ayında kapatıldı. Primer olan başka bir olguda mide tümörünün karaciğer sol lobunu ve pankreas gövdesini invaze etmesi sebebiyle sol hepatektomi ve subtotal pankreatektomi eklendi. Olguların ek organ rezeksiyonları Tablo $5^{\prime}$ te özetlenmiştir. Komplikasyon açısından yapılan değerlendirmede; bir olguda erken dönem özefagojejunustomi anastomoz kaçağı saptanarak, komplikasyonun kontrolü özefogostomi ve beslenme jejunostomisiyle sağlandı. Hiçbir hastamızda erken dönemde mortalite görülmezken kaçak nedeniyle özefagostomi uygulanan hasta takibinin 4. ayında hastane kaynaklı pnömoni nedeniyle kaybedilmiştir. Dokuz olgunun

\begin{tabular}{|c|c|}
\hline Özellikler & Median (SS) \\
\hline Yaş & $60,3(45-68)$ \\
\hline $\begin{array}{r}\text { Cinsiyet } \\
\text { Erkek } \\
\text { Kadın }\end{array}$ & $\begin{array}{l}7 \\
3 \\
\end{array}$ \\
\hline $\begin{array}{c}\text { ASA } \\
1 \\
2 \\
3\end{array}$ & $\begin{array}{l}3 \\
4 \\
3\end{array}$ \\
\hline VYA & $1,68(1,3-1,8)$ \\
\hline PKi skoru & $9,9(7-16)$ \\
\hline $\begin{array}{c}\text { CC skoru } \\
1 \\
2\end{array}$ & $\begin{array}{l}7 \\
3\end{array}$ \\
\hline Hastanede yatış (gün) & $9(7-30)$ \\
\hline Anastomoz sayısı & $1,8(0-3)$ \\
\hline $\begin{array}{l}\text { İleostomi kapatılması } \\
\text { Evet } \\
\text { Hayır }\end{array}$ & $\begin{array}{l}+ \\
-\end{array}$ \\
\hline $\begin{array}{l}\text { Clavien-Dindo komplikasyon skoru } \\
1 \\
2 \\
3 \mathrm{~A} \\
3 \mathrm{~B} \\
4 \\
5\end{array}$ & $\begin{array}{l}2 \\
4 \\
3 \\
0 \\
1 \\
0\end{array}$ \\
\hline
\end{tabular}




\begin{tabular}{|c|c|c|c|c|}
\hline Olgu & Geçirilmiş operasyon & Ameliyat & Süre & Morbimortalite \\
\hline 1 & Primer mide $\mathrm{Ca}+\mathrm{PK}$ & $\mathrm{TG}+\mathrm{R} \& Y$ + D2 LND SRC + HIPEC & $7 \mathrm{~s}$ & yok \\
\hline 2 & 3 yıl önce subtotal Gastrektomi + Billroth2 & Totale tamamlama + R\&Y + SRC + HiPEC & $8 s$ & Anastomoz kaçağı \\
\hline 3 & Primer mide $\mathrm{Ca}+\mathrm{PK}$ & $\mathrm{TG}+\mathrm{R} \& \mathrm{Y}+\mathrm{D} 2 \mathrm{LND} S \mathrm{SRC}+\mathrm{HI} \mathrm{PEC}$ & $6,5 s$ & Nötropeni \\
\hline 4 & 1 yıl önce TG + R\&Y +D2 LND & SRC + HIPEC & 9s & Plevral efüzyon \\
\hline 5 & 7 ay önce TG + R\&Y + D2 LND & SRC + HIPEC & $8,5 \mathrm{~s}$ & Plevral efüzyon \\
\hline 6 & Primer mide $\mathrm{Ca}+\mathrm{PK}$ & $\mathrm{TG}+\mathrm{R} \& \mathrm{Y}+\mathrm{D} 2 \mathrm{LND}$ SRC + HIPEC & $6 s$ & Kanama \\
\hline 7 & 10 ay önce Gastrojejunostomi & TG + R\&Y +D2 LND SRC + HIPEC & $7 \mathrm{~s}$ & Nötropeni \\
\hline 8 & Primer mide $\mathrm{Ca}+\mathrm{PK}$ & TG + R\&Y + D2 LND SRC + HIPEC & $7 \mathrm{~s}$ & yok \\
\hline 9 & Primer mide $\mathrm{Ca}+\mathrm{PK}$ & TG +R\&Y + D2 LND SRC + HIPEC & $7,5 \mathrm{~s}$ & Plevral efüzyon \\
\hline 10 & Primer mide $\mathrm{Ca}+\mathrm{PK}$ & $\begin{array}{l}\text { Total kolektomi + IAJPA + TG + R\&Y + D2 } \\
\text { LND SRC + HIPEC }\end{array}$ & $10 \mathrm{~s}$ & yok \\
\hline
\end{tabular}

\begin{tabular}{|c|c|}
\hline Organ rezeksiyonları (n) & Yapılan işlem sayıları (SS) \\
\hline Omentum & 7 \\
\hline Diyafram & 2 \\
\hline İleum-jejenum & 3 \\
\hline Karaciğer & $\begin{array}{l}4 \text { olguda segmentektomi } \\
1 \text { olguda sol lateral segmentektomi } \\
1 \text { vakada sol lobektomi }\end{array}$ \\
\hline Kolonrektum & 3 \\
\hline Pankreas & 2 \\
\hline Safra kesesi & 3 \\
\hline Dalak & 3 \\
\hline $\begin{array}{l}\text { Paraaortik lenf nodu } \\
\text { diseksiyonu }\end{array}$ & 2 \\
\hline $\begin{array}{l}\text { Total abdominal histerektomi + } \\
\text { Bilateral salpingooferektomi }\end{array}$ & 1 \\
\hline \multicolumn{2}{|c|}{$\begin{array}{l}\text { SD: Standart sapma, CRS: Sitoredüktif cerrahi, HIPEC: Hipertermik intraperitoneal } \\
\text { kemoterapi }\end{array}$} \\
\hline
\end{tabular}

takip ve tedavisi devam etmekte olup en uzun takip süresine sahip olan olgumuz 15. ayındadır.

\section{Tartışma}

Mide kanserinin daha sık görüldü Japonya, Çin ve Kore gibi ülkelerde peritoneal karsinomatozisin eşlik etmesinde sağkalım 1 yıldan daha az olup primer tümör kontrol altına alınsa dahi 5 yıllık sağkalımın olmadığı bildirilmektedir $(3,13,14)$. Mide serozasının invazyonuyla hastalık yeni bir aşamaya geçip bu aşamada lenf nodu istasyonlarındaki metastazlar daha sıklıkla saptanmaktadır. Serozal tutulunumun bir diğer sonucuda tümör hücrelerinin dökülerek peritoneal karsinomatoza öncülük etmesidir (15). Yapılan araştırmalarda mide kanserinin solid organ metastazları ve buna bağlı gelişen mortaliye oranı \%40'larda iken daha erken mortalite ile giden peritoneal karsinomatozisin eşlik ettiği durumda ise bu oran \%60'lardadır $(16,17)$.

Günümüzde peritoneal karsinomatozisli kolorektal ve jinekolojik kanserlerdeki sağkalıma olumlu etkisi gösterilmiş etkenler yeni kuşak sistemik kemoterapotikler ve uygun hastalarda yapılan SRC + HIPEC işlemidir (18). SRC + HIPEC uygulamasından alınan olumlu sonuçlar multidisipliner hasta yaklaşımıyla, daha agresif seyreden pankreas ve mide kanserlerinde uygulanabilirliğinin son iki dekatta sorgulanmasına neden olmuştur (19). Özellikle Asya toplumlarında daha sık gözüken ve dünyada kansere bağlı ölümlerde üçüncü sırada olan mide kanserinde sağ kalımı uzatmaya yönelik yeni stratejiler araştırmalarda geniş yer bulmuş ve bunun sonucu olarak günümüzde ileri evre mide kanserlerinde neoadjuvan kemoterapotikler ve profilaktik HIPEC uygulaması güncel literatürde yerini almaya başlamıştır (14).

Abdominal diğer organların kanserlerinde solid organ metastazları daha sık gözükürken mide kanserlerinde metastazın en fazla görüldüğü bölge peritondur. PK'nin geliştiği durumlarda sağkalım 3-6 ayla sınırlı olup beslenme bozukluğuna ve kansere bağlı mortalite kısa sürede gelişebilmektedir. Başlıca apendiks, mezotelyoma, over ve kolon kanseri kaynaklı peritoneal karsinomatozisde SRC + HiPEC'nin olumlu etkisi; mide kanserinin periton metastazlarındada yer alabileceğini düşündürmüştür. Fakat bu durum mide kanserinde yaygın implantlardan ziyade, lokal ileri rezektabl hastalıktada SRC + HiPEC uygulanması yönündedir. Tu ve ark. (15) tarafından yapılan bir çalışmada mide kanserinde SRC + HIPEC uyguladıkları 231 hastada bir yıllık sağkalımı \%84 olarak saptamış olup yöntemin efektif ve güvenli bir modalite olduğunu bildirmişlerdir. Yine Avrupa'dan Yarema ve ark. (7) tarafından yapılan 
başka bir çalışmada ise uygun hastalarda SRC ve HiPEC'nin sağkalıma olumlu katkıları olduğu ve sağkalımı 22,5 aya kadar çıkardığı bildirilmiştir. Bu çalışmada yine işlemin güvenli ve hastalar tarafından iyi tolere edildiğide vurgulanmıştır.

SRC + HiPEC uygulamasının ilk tanımlandığı süreçten itibaren cerrahları, böyle bir agresif cerrahi sonrasında metabolizmayada katabolik etkileri olabileceği gösterilen yüksek basınçlı HIPEC uygulamasının komplikasyonlara neden olabileceğini gündeme getirmiştir. Bu konuda ilk uygulanan yıllarda her ne kadar kolorektal cerrahide normal kanser cerrahisine göre SRC + HIPEC uygulamasında daha fazla morbidite (yara problemleri, ileus, anastomoz kaçakları) bildirilmişe de son 20 yılda ekiplerin multidisipliner olarak çalışı daha fazla deneyim elde etmesiyle bu oranlar normal kanser cerrahisi ile benzer hale gelmiştir (14).

SRC'de hem postoperatif gelişebilecek komplikasyonların hemde sağkalıma etkisi konusundaki en iyi tanımlanmış parametrelelerden biride Sugarbaker (20) tarafından tanımlanan peritoneal karsinomatozis indeks skorudur. Bu skorlama sisteminde abdominal boşluk 13 bölgeye ayrılarak implantların büyüklüğüne görede 0'dan 3'e kadar derecelendirilmektedir. Bu elde edilen skor ile şu anki güncel literatürde abdominal kaynaklı kolorektal gibi tümörlerde skorun 20'ye kadar olması bu işlemin uygulanabilirliğini göstermektedir. Coccolini ve ark. (21) PCl cut-off değerini 12 olarak bildirmişler bunun üzerindeki değerlerin kötü prognozla seyrettiğini vurgulamışlardır. Son olarak, Chia ve ark. (22) tarafından yapılan çalışmada PCl skorunun 7'nin üzerinde olmaması mide kanserinde de bu işlemin uygulanabileceğini bildirmişlerdir. Ameliyat sonrası gelişebilecek morbidite ve mortaliteye etki eden diğer faktörler ise yapılan ek organ rezeksiyonları ve hastaların preop dönemdeki ek hastalıklarıdır (23). Prosedür öncesi multidisipliner yaklaşımla ek hastalıklar açısından ameliyat sonrası sürecin başarılı geçmesi için ek hastalıkların yönetimi ayrı bir önem arz etmektedir. Bir diğer gösterilen morbidite ve mortaliteye etkisi olan faktör ek organ rezeksiyonları olup bu konuda yapılan çalışmalar en fazla hepatopankreatobiliyer girişimlerin etkisi olabileceğini göstermektedir. Bizim 10 olgumuzun dördünde majör hepatopankreatobiliyer girişim yapılmış olup bu dört olgudan birisinde sol hepatektomi + subtotal pankreatektomi, bir diğerinede sol lateral segmentektomi yapılmış olup herhangi bir komplikasyon gelişmemiştir. Bu noktada cerrahi onkololoji ile beraber olguların hepatopankreatobiliyer aşamasında bu konuda deneyimli bir cerrahın operasyona dahil olmasının olumlu etkisi olduğu kanaatindeyiz.

Mide kanseri için yapılan radikal gastrektomi sonrasında morbidite ve mortalite oranları Wu Z ve ark. (24) tarafından yapılan çalışmada sırasıyla yaklaşık \%20 ve \%5 oranında gösterilmiştir. Hastalığın gerek komplikasyon sürecinin yönetimi, gerek sağ kalıma katkısı olacağı düşünülen SRC HIPEC uygulaması yine bu merkezlerde geniş yer bulmuştur. Biz de, bu bilgiler ışığında gerek primer gereksede nüks sonrası mide kanserinde SRC sonrası uyguladığımız ilk 10 olgumuzda bir hastada erken dönem komplikasyon olarak anastomoz kaçağı görüldü bu durum özefagostomi ile kontrol altına alındı. Sağkalım açısından olgularımız değerlendirildiğinde en uzun takip süresine sahip olgumuz 15. ayında olup, olgularımızda şu ana kadarki takiplerinde nüks saptanmamış olup hastaların taburculuk sonrası post op sistemik KT'si planlanmıştır.

\section{Sonuç}

Güncel tedavi stratejilerinin bir tanesinide intraperitoneal kemoterapi ile neoadjuvan kemoterapi tedavisinin birlikte uygulanması olup bunun overall survivala ve hastalıksız sağkalıma olumlu etkileri olduğu bildirilmektedir.

Bu sonuçlar ışığında literatüre katkısı olacağını düşündüğümüz peritoneal karsinomatozisli mide kanserlerinde total gastrektomi R\&Y özefagojejunostomi D2 lenf nodu diseksiyonuna eklenen SRC + HIPEC uygulamasındaki deneyimimizi sunmakla beraber, daha fazla randomize kontrollü çalışmalara intiyaç vardır.

Yakın gelecekte PK veya ileri evre olmayan mide kanserlerinde de HIPEC uygulamasının gündeme geleceğini düşünmekteyiz.

\section{Yazarlık Katkıları}

Konsept: Ö.D. Dizayn: S.Y., M.K. Veri Toplama veya İşleme: Ş.Ç., M.K., S.Y.L. Analiz veya Yorumlama: Ö.D., N.K., Ö.F.Ö. Literatür Arama: S.Y., Ş.Ç. Yazan: Ö.D.

Çıkar Çatışması: Yazarlar tarafından çıkar çatışması bildirilmemiştir.

Finansal Destek: Yazarlar tarafından finansal destek almadıkları bildirilmiştir.

\section{Kaynaklar}

1. Ferlay J, Soerjomataram I, Dikshit R, et al. Cancer incidence and mortality worldwide: sources, methods and major patterns in GLOBOCAN 2012. Int J Cancer 2015;136: e35986.

2. Polom K, Marano L, Roviello G, et al. Evolution and emerging future of cytoreductive surgery and hyperthermic intraperitoneal chemoperfusion in gastric cancer: From treating the incurable to preventing recurrence. Int J Hyperthermia 2016;32:173-9.

3. Geng X, Liu H, Lin T, et al. Survival benefit of gastrectomy for gastric cancer with peritoneal carcinomatosis: a propensityscore matched analysis. Cancer Med 2016;5:278191. 
4. Kim GH, Liang PS, Bang SJ, et al. Screening and surveillance for gastric cancer in the United States: Is it needed? Gastrointest Endosc 2016;84:18-28.

5. Maeda H, Kobayashi M, Sakamoto J. Evaluation and treatment of malignant ascites secondary to gastric cancer. World J Gastroenterol 2015;21:10936-47.

6. Ji ZH, Peng KW, Yu Y, et al. Current status and future prospects of clinical trials on CRS + HIPEC for gastric cancer peritoneal metastases. Int J Hyperthermia 2017;33:562-70.

7. Yarema RR, Ohorchak MA, Zubarev GP, et al. Hyperthermic intraperitoneal chemoperfusion in combined treatment of locally advanced and disseminated gastric cancer: results of a single-centre retrospective study. Int J Hyperthermia 2014;30:159-65.

8. Seshadri RA, Glehen O. Cytoreductive surgery and hyperthermic intraperitoneal chemotherapy in gastric cancer. World J Gastroenterol 2016;21:1114-30.

9. Boerner T, Graichen A, Jeiter T, et al. CRS-HIPEC Prolongs Survival but is Not Curative for Patients with Peritoneal Carcinomatosis of Gastric Cancer. Ann Surg Oncol 2016;23:3972-7.

10. Morales-Soriano R, Esteve-Pérez N, Segura-Sampedro JJ, et alCurrent practice in cytoreductive surgery and HIPEC for metastatic peritoneal disease: Spanishmulticentric survey. Eur J Surg Oncol 2018;44:228-36.

11. Ellison LM, Man Y, Stojadinovic A, Xin H, Avital I. Cytoreductive surgery and hyperthermic intraperitoneal chemotherapy in treatment of gastric cancer with peritoneal carcinomatosis. Chin J Cancer Res 2017;29:86-92

12. Sun J, Song $Y$, Wang $Z$, et al. Benefits of hyperthermic intraperitoneal chemotherapy for patients with serosal invasion in gastric cancer: a meta-analysis of the randomized controlled trials. BMC Cancer 2012;12:526-9.

13. Braam HJ, Schellens JH, Boot $H$, et al. Selection of chemotherapy for hyperthermic intraperitoneal use in gastric cancer. Crit Rev Oncol Hematol 2015;95:282-96.

14. Coccolini F, Cotte $E$, Glehen $O$, et al. Intraperitoneal chemotherapy in advanced gastric cancer. Meta-analysis of randomized trials. Eur J Surg Oncol 2014;40:12-26.
15. Tu $Y$, Tian $Y$, Fang $Z$, et al. Cytoreductive surgery combined with hyperthermic intraperitoneal chemoperfusion for the treatment of gastric cancer: A single-centre retrospective study. Int J Hyperthermia 2016;32:587-94.

16. Wei J, Wu ND, Liu BR. Regional but fatal: Intraperitoneal metastasis in gastric cancer. World J Gastroenterol 2016;22:7478-85.

17. Feingold PL, Kwong ML, Davis JL, et al. Adjuvant intraperitoneal chemotherapy for the treatment of gastric cancer at risk for peritoneal carcinomatosis: A systematic review. J Surg Oncol 2017;115:192-201.

18. Murata S, Yamamoto $H$, Naitoh $H$, et al. Feasibility and safety of hyperthermic intraperitoneal chemotherapy using 5 fluorouracilcombined with cisplatin and mitomycin $C$ in patients undergoing gastrectomy for advancedgastric cancer. J Surg Oncol 2017;116:1159-65.

19. Tentes AA, Pallas N, Karamveri $C$, et al. Cytoreduction and HIPEC for peritoneal carcinomatosis of pancreatic cancer. J BUON 2018;23:482-87.

20. Sugarbaker PH. Peritoneal surface oncology: review of a personal experience with colorectal and appendiceal malignancy. Tech Coloproctol 2005;9:95-103.

21. Coccolini F, Catena F, Glehen $O$, et al. Complete versus incomplete cytoreduction in peritoneal carcinosis from gastric cancer, with consideration to $\mathrm{PCl}$ cut-off. Systematic review and meta-analysis. Eur J Surg Oncol 2015;41:911-9.

22. Chia CS, You B, Decullier E, et al. Patients with Peritonea Carcinomatosis from Gastric Cancer Treated with Cytoreductive Surgeryand Hyperthermic Intraperitoneal Chemotherapy: Is Cure a Possibility? Ann Surg Oncol 2016;23:1971-9.

23. Wu HT, Peng KW, Ji ZH, et al. Cytoreductive surgery plus hyperthermic intraperitoneal chemotherapy with lobaplatin and docetaxel to treat synchronous peritoneal carcinomatosis from gastric cancer: Results from a Chinese center.Eur J Surg Oncol 2016;42:1024-34.

24. Wu Z, Li Z, Ji J. Morbidity and mortality of cytoreductive surgery with hyperthermic intraperitoneal chemotherapy in advanced gastric cancer. Transl Gastroenterol Hepatol 2016;1:63 